\title{
O potencial de Streptomyces isolados na região de maués na produção de enzimas hidrolíticas
}

The streptomyces potential in isolated from maues region in hydrolytic enzymes production

\author{
Leila Viviane Araujo Coelho, Camila Beatriz Atanásio Borba, Erik Jonne Vieira de Melo \\ e Leonor Alves de Oliveira da Silva
}

Universidade Federal de Pernambuco-Recife-Pernambuco, Brasil

leilavacoelho11@hotmail.com; camilaborbaster@gmail.com; erikjonne@hotmail.com; laodls@yahoo.com.br

\section{Resumo}

A área de produção de enzimas microbianas tem crescido nas últimas décadas, devido à utilização nos diversos campos industriais e com isso a necessidades de pesquisas com inovações dos produtos já existentes. As enzimas hidrolíticas são catalizadores biológicos com alta aplicabilidade em diversas áreas da biotecnologia industrial. A castanha-do-Brasil é uma possivel fonte de nutrientes para o crescimento de micro-organismos em busca de produção enzimática efetiva e de baixo custo. Foram utilizados 2 linhagens de Streptomyces sp. para a produção de protease, lipase, amilase e fosfatase alcalina utilizando o resíduo de castanha-do-Brasil como fonte de carbono em fermentação em estado sólido e submersa em meio ISP-2 no pH 7,2 a $37^{\circ} \mathrm{C}$ por 15 dias. Os resultados obtidos evidenciaram que a melhor atividade enzimática foi para a protease excretada pela Streptomyces $s p$. (1N) em fermentação semi-sólida. Concomitante, foi realizada uma cinética de produção enzimática com pico de atividade de 0,196 U/mL durante 144 horas. Na atividade especifica observou-se um valor de 2,17 U/mg de proteina durante 240 horas. A produção de enzimas excretada por Streptomyces. sp utilizando o resíduo de castanha-do-Brasil é um recurso para obtenção de enzimas com elevado potencial para fermentação semi-sólida.

Palavras-chave: Enzimas hidroliticas; Streptomyces sp.; Castanha-do-Brasil

\section{Abstract}

The enzymes of microbial production area has grown in the last decades due to use in various industrial fields, and with that the research needs to innovations of existing products. The hydrolytic enzymes are biological catalysts of great commercial importance for low cost and high availability. This enzyme class has received special attention about his versatility in several areas of industrial biotechnology. The Brazil-nuts is a possible source of nutrients for the growth of micro-organisms in search of effective enzyme production and low cost. Were used two strains of Streptomyces sp. or production of protease, lipase, amylase and alkaline phosphatase using the residue Brazil-nut as carbon source in fermentation, semi-solid and liquid for the medium ISP-2 at pH 7.2 at a temperature $37^{\circ} \mathrm{C}$ for 15 days. The results showed that the best enzymatic activity was to protease secreted by Streptomyces $s p$. (1N) in semi solid fermentation. Concomitantly, was carried out an enzyme production kinetics with peak activity of 0.196 $\mathrm{U} / \mathrm{ml}$ activity for 144 hours. The specific activity was observed a value of $2.17 \mathrm{U} / \mathrm{mg}$ protein for 240 hours. The production of enzymes excreted by Streptomyces sp. using the residue of Brazil-nuts is a resource for obtaining enzymes with high potential for solid state fermentation.

Keywords: Hydrolytic enzymes; Streptomyces sp.; Brazil nuts 


\section{Introdução}

As enzimas são substâncias orgânicas específicas, compostas por polímeros de aminoácidos, que atuam como catalisadores no metabolismo dos seres vivos (ROSAS; PANTANO FILHO, 2003). Devido sua alta aplicabilidade biotecnológica, a tecnologia enzimática se apresenta como uma opção interessante e rentável para a exploração econômica uma vez que desempenha diversos tipos de reações A aplicação de diferentes tipos de enzimas nas indústrias tem a possibilidade de tornar o processo biotecnológico mais proveitoso, com elevados rendimentos e baixos danos ao meio ambiente (HASAN; SHAH; HAMEED, 2006).

Enzimas hidrolíticas são as mais utilizadas nos processos industriais, sendo aplicadas na hidrólise de várias substâncias naturais. Os grupos das proteases constituem o maior grupo de enzimas utilizadas industrialmente no mundo, movimentando a economia deste setor ativamente (PILLAI et al., 2011). Estas enzimas têm como função hidrolisar ligações peptídicas (LI et al., 2012) e podem ser obtidas de diferentes fontes, entretanto as proteases microbianas se destacam pela sua metabolização e baixo custo (AWAD et al., 2013; MOSTAFA et al., 2012).

As amilases estão entre as mais importantes enzimas industriais, são aplicadas como aditivos em detergentes, indústrias de alimentos, fermentação, papel e têxtil, farmacêutica, médica e químico-analítica (PANDEY et al., 2000; SOARES et al., 2010).

As enzimas lipolíticas catalisam a hidrólise de gorduras e óleos, são consideradas o terceiro maior grupo baseado no volume total de compras, onde o uso comercial foi estimado em um bilhão (JAEGER et al., 1999). Possuem diversas aplicações industriais, utilizadas como biocatalisadores ideais em química orgânica entre outros (TREICHEL et al., 2010; LOU et al., 2013; SHARMA; KANWAR, 2014).

As fosfatases agem sobre compostos de fósforo, podendo hidrolisar uma variedade de ésteres e anidridos do ácido fosfórico e liberar fosfato, além de atuar em reações de transfosforilação de fosfoésteres de glicerol, fenol e $\rho$ nitrofenol, para vários aceptores, como, piridoxina e glicose (ZIMMER et al., 2009).

As actinobactérias apresentam diversas propriedades metabólicas e fisiológicas, com grande variedade de metabólitos secundários e produção de enzimas extracelulares de alta aplicabilidade nas indústrias (RAJU et al., 2010; ANZAI et al., 2008, DURAIPANDIYAN et al., 2010). As Streptomyces e outros actinomicetos são responsáveis por grande parte dos produtos metabólicos com atividade biotecnológicos (GAMA et al., 2012; PACHECO DA ROSA et al., 2013).

A castanha-do-Brasil é de grande importância na formação econômica, social e política da Amazônia, e está entre os produtos mais comercializados no mercado nacional e de exportação (SÁ et al., 2008; HOMMA et al., 2012). Este produto é rico em compostos químicos que servem como nutrientes para o crescimento de micro-organismos em busca de produção enzimática efetiva. Estima-se que a produção dos resíduos de ouriço de castanha seja elevada, pois o ouriço possui peso médio de 2,4 kg, sendo aproximadamente 1,0 kg de castanhas limpas e 1,4 kg de resíduos (biomassa residual), incluindo as cascas da castanha bruta (CRUZ-JÚNIOR et al., 2010). A castanha-do-Brasil, devido ao seu grande valor econômico, está envolvida em numerosos processos industriais, onde grandes quantidades de resíduos são gerados (PACHECO; VILDES, 2006).

Neste contexto, objetivou-se avaliar a produção de enzimas hidrolíticas (proteases, lipases, fosfatases alcalinas e amilases) por duas linhagens de Streptomyces isoladas do solo amazônico, em fermentações utilizando resíduos de castanha-do-Brasil como fonte de carbono. 


\section{Material e método}

\subsection{Obtenção dos resíduos}

As amostras do resíduo da castanha-do-Brasil para análises bioquímicas foram obtidos a partir de trituração do material em liquidificador multiprocessador da marca ARNO, até a obtenção de uma farinha fina com granulometria menor que $0,60 \mathrm{~mm}$, realizada em peneira. A torta foi obtida após o processo físico de extração a frio por prensagem em prensa hidráulica em temperatura ambiente a $30^{\circ} \mathrm{C}$.

\subsection{Caracterização bioquímica do resíduo de Castanha-do-Brasil}

Para a determinação da composição centesimal do resíduo de castanha-do-Brasil, que consistiu da extração bioquímica de lipídeos, compostos polares, compostos apolares, celulose, hemicelulose e lignina seguiu-se a metodologia descrita por Melo (2010) e foram utilizados 3 gramas das amostras para realização em três etapas. A primeira etapa refere-se à extração com solvente ciclohexano, a segunda com álcool etílico e a terceira com água. Para obtenção dos resultados referentes à celulose, hemicelulose e lignina, esta metodologia segue as normas da Associação Brasileira de Papel e Celulose e a NBR 7989:2010 (pasta celulósica e madeira determinação de lignina insolúvel em ácido), na qual a amostra foi submetida a uma extração ácida por um sistema de refluxo para a caracterização da celulose e da hemicelulose e depois à calcinação, na temperatura de $750^{\circ} \mathrm{C}$.

\subsection{Micro-organismo Utilizados e Identificação}

Foram reativadas duas linhagens de Streptomyces $s p$., as quais se destacaram em trabalhos anteriormente desenvolvidos pelo referido grupo de pesquisa, que foram isoladas e identificadas morfologicamente em nível de gênero. A identificação das linhagens estudadas no referido trabalho, foi realizada por meio da técnica de microcultivo para análise micromorfológica segundo o método descrito por Holt e colaboradores (1989). Após crescimento foram realizadas análises microscópicas e macroscópicas para evidenciar cor do micélio sob o substrato, coloração de micélio aéreo e ausência ou produção de pigmentos. As características morfológicas das actinobactérias tais como: ramificação do micélio sobre o substrato, formação de micélio aéreo e sua fragmentação ou produção de esporos, foram fatores que auxiliaram na identificação das actinobactérias. Neste gênero observou-se também o tipo e o número de esporos, bem como o seu arranjo. Estas actinobactérias foram denominadas: $1 \mathrm{~N}$ e $4 \mathrm{H}$, isoladas e identificadas morfologicamente da rizosfera de Paullinia cupana (Guaraná) da região de Maués AM Latitude $03^{\circ} 23^{\prime} 01^{\prime \prime}$ sul e longitude $57^{\circ} 43^{\prime} 07^{\prime \prime}$ oeste, com altitude de 25 metros acima do nível do mar, cedidas e preservadas na coleção de micro-organismo do Departamento de Antibióticos da Universidade Federal de Pernambuco (UFPEDA). As cepas microbianas foram cultivadas em meio líquido ISP-2 (extrato de levedura 4,0 g/L, extrato de malte $10 \mathrm{~g} / \mathrm{L}$, dextrose 4,0 g/L pH 7,2) sob agitação de $180 \mathrm{rpm}$ a $37^{\circ} \mathrm{C}$ por 48 horas. Posteriormente repicadas em meio sólido: ISP2, ISP3, ISP4, ISP7 e ALA, e incubados a $37^{\circ} \mathrm{C}$ por um período de 7 a 10 dias.

\subsection{FES - fermentação em estado sólido e fermentação submersa}

Para preparar o pré-inóculo, cinco discos de $0,9 \mathrm{~mm}$ de diâmetro de cada uma das linhagens de Streptomyces $1 \mathrm{~N}$ e $4 \mathrm{H}$ (meio sólido ISP2 a $37^{\circ} \mathrm{C}$ por 7 dias) foram inoculadas separadamente em $50 \mathrm{~mL}$ de meio líquido ISP2 incubadas por 48 horas a $37^{\circ} \mathrm{C}$ sob agitação de $120 \mathrm{rpm}$. 
$\mathrm{Na}$ fermentação semi-sólida, $5 \mathrm{~mL}$ deste pré-inóculo foram inoculados em Erlenmeyer de $250 \mathrm{~mL}$, contendo 5,0 g de resíduo de castanha-do-Brasil esterilizado, a $37^{\circ} \mathrm{C}$ por 15 dias (condições previamente estudadas em trabalhos anteriormente realizados pelo grupo de pesquisa). No término da fermentação em estado sólido, em cada Erlenmeyer foram adicionados $20 \mathrm{~mL}$ de água destilada estéril acrescida de $500 \mu \mathrm{L}$ de Tween 80 , submetido à agitação mecânica de $150 \mathrm{rpm}$ por 15 minutos. Posteriormente submetido à filtração utilizando papel filtro Qualy $14 \mu \mathrm{m}$ para obtenção do complexo enzimático.

No estudo da fermentação submersa $5 \mathrm{~mL}$ dos pré-inóculos, foram inoculados em Erlenmeyer de $250 \mathrm{ml}$, contendo $50 \mathrm{~mL}$ do meio líquido ISP2- modificado, onde a glicose foi substituída por 5,0 g de resíduo de castanha-doBrasil, incubados a $37^{\circ} \mathrm{C}$ em condição estacionária (sem agitação) por 7 dias. A extração do complexo enzimático foi obtida por filtração a vácuo utilizando papel filtro Qualy $14 \mu \mathrm{m}$, os sobrenadantes foram designados de complexos enzimáticos e armazenados em microtubos e imediatamente submetidos às dosagens enzimáticas e proteicas.

\subsection{Determinação de Atividade Amilolítica}

A atividade enzimática da amilase sacarificante foi determinada utilizando $100 \mu \mathrm{L}$ de solução de amido a $1 \%$ em tampão acetato de sódio $50 \mathrm{mM}$ com pH 6,0 e $50 \mu \mathrm{L}$ de extrato enzimático. O controle da reação foi preparado conforme o processo descrito, substituindo-se a enzima por volume equivalente de água destilada (controle do substrato). O segundo controle foi realizado substituindo-se a solução de amido por volume de tampão acetato de sódio $50 \mathrm{mM}$ pH 6,0 (controle da enzima). Incubou-se a $37^{\circ} \mathrm{C}$ por 30 minutos. A reação foi interrompida pela adição de $250 \mu \mathrm{L}$ ácido 3',5'-dinitrosalicílico (DNS), segundo Miller (1959). Em seguida, as amostras foram submergidas em banho fervente por 5 minutos. Foi adicionado $1 \mathrm{~mL}$ de água destilada, a seguir, a leitura das amostras foi realizada em espectrofotômetro a $550 \mathrm{~nm}$ contra o branco, neste o extrato enzimático foi substituído por água destilada. O sistema foi padronizado por uma curva de concentração molar de glicose. Uma unidade (U) de atividade amilásica sacarificante foi determinada como a quantidade de enzima necessária para liberar $1 \mu \mathrm{mol}$ de açúcar redutor por minuto nas condições de ensaio. Os ensaios foram realizados em triplicata.

\subsection{Determinação de Atividade Lipolítica}

Foi usada uma solução de $2 \mathrm{~g}$ de Triton X-100, 0,5 g de goma arábica em $450 \mathrm{~mL}$ de tampão fosfato de sódio $50 \mathrm{mM}, \mathrm{pH} 8,0$ e palmitato de p-nitrofenila em isopropanol $15 \mathrm{mM}$ e adicionando posteriormente, $55 \mu \mathrm{L}$ do extrato enzimático. Em seguida, foi incubado a $37^{\circ} \mathrm{C}$ por 30 minutos e sua leitura foi realizada a $410 \mathrm{~nm}$. Uma unidade (U) de atividade enzimática foi definida como a quantidade de enzima capaz de liberar $1 \mu \mathrm{mol}$ de para-nitrofenol/ $\mathrm{mL}$ sob as condições do ensaio. Os ensaios foram realizados em triplicata (ROWE, L; HOWAR, G.T., 2002, COLLA et al., 2012).

\subsection{Determinação de Atividade Proteolítica}

A atividade proteolítica foi determinada utilizando $50 \mu \mathrm{L}$ de azocaseína $1 \%$ em tampão Tris- $\mathrm{HCl} 50 \mathrm{~mm}, \mathrm{pH}$ 8,5. Após, incubado a $45^{\circ} \mathrm{C}$ por 1 hora. A mistura reacional foi interrompida pela adição de $240 \mu \mathrm{L}$ de ácido tricloroacético (TCA) a 10\% e, em seguida as amostras foram centrifugadas por 5 minutos, a 10.000 rpm. A reação foi neutralizada pela adição de $280 \mu \mathrm{L}$ de $\mathrm{NaOH} 1 \mathrm{M}$ a $160 \mu \mathrm{L}$ do sobrenadante, a seguir a leitura das amostras foi realizada em espectrofotômetro a $440 \mathrm{~nm}$, metodologia adaptada por DAROIT et al. (2009). Uma unidade (U) de atividade proteolítica foi definida como a quantidade de enzima necessária para aumentar na absorbância de 0,001 a 440nm utilizando azocaseína como substrato. Os ensaios foram realizados em triplicata. 


\subsection{Determinação de Atividade da Fosfatase Alcalina}

A atividade da fosfatase alcalina foi determinada por meio de dosagens espectrofotométricas utilizando o Kit comercial In vitro (doles 14021). A absorbância utilizada foi $405 \mathrm{~nm}$. Os ensaios foram realizados em triplicata. Uma unidade $(\mathrm{U})$ de atividade enzimática foi definida como a quantidade de enzima capaz de liberar $1 \mu \mathrm{mol}$ de paranitrofenol/ $\mathrm{mL}$ sob as condições do ensaio. Em todos os ensaios realizados as proteínas totais foram quantificadas seguindo a metodologia de Bradford (1976).

\section{Resultados e discussão}

No presente estudo o resíduo de castanha-do-Brasil, utilizado como fonte de carbono para produção dos complexos enzimáticos excretados pelas duas linhagens de Streptomyces sp., apresentou na caracterização, concentrações de $10 \%$ de compostos não polares, $12,83 \%$ de compostos polares, $12,69 \%$ de hemiceluloses, $4,51 \%$ de lignina, e 56,09\% de lipídios, indicando a presença de fontes nutricionais disponíveis ao metabolismo microbiano. Santos (2008), trabalhando com amêndoas de castanha-do- Brasil detectou valores de 65,33\% de lipídeos.

Nas Figuras 1 e 2, são mostrados os resultados dos valores das atividades enzimáticas em U/mL e U/mg de proteína, obtidos nos ensaios de fermentação em estado sólido e submersa utilizando o resíduo de castanha-do-Brasil inoculadas com as duas linhagens de Streptomyces $s p$. $1 \mathrm{~N}$ e $4 \mathrm{H}$, para a produção extracelular dos complexos enzimáticos (proteases, lipases, amilases e fosfatases alcalinas). Ainda de acordo com as figuras 1 e 2 , as melhores produções dos complexos enzimáticos ocorreram nos ensaios de fermentação em estado sólido produzidos pelas Streptomyces $1 \mathrm{~N}$ e $4 \mathrm{H}$.

Analisando o complexo lipolítico excretado pela linhagem 1N, comparando os dois métodos fermentativos, observou-se maior produção nas fermentações em estado sólido com atividades em U/mL e U/mg de proteína com 4,09 vezes e 2,78 vezes superiores aos respectivos valores obtidos nas fermentações submersas. Nos ensaios amilolíticos em fermentação em estado sólido a produção da referida enzima pela linhagem $1 \mathrm{~N}$, medidas em $\mathrm{U} / \mathrm{mL}$ e U/mg de proteína foram respectivamente 1,91 e 1,94 vezes superiores aos valores detectados nas fermentações submersas.

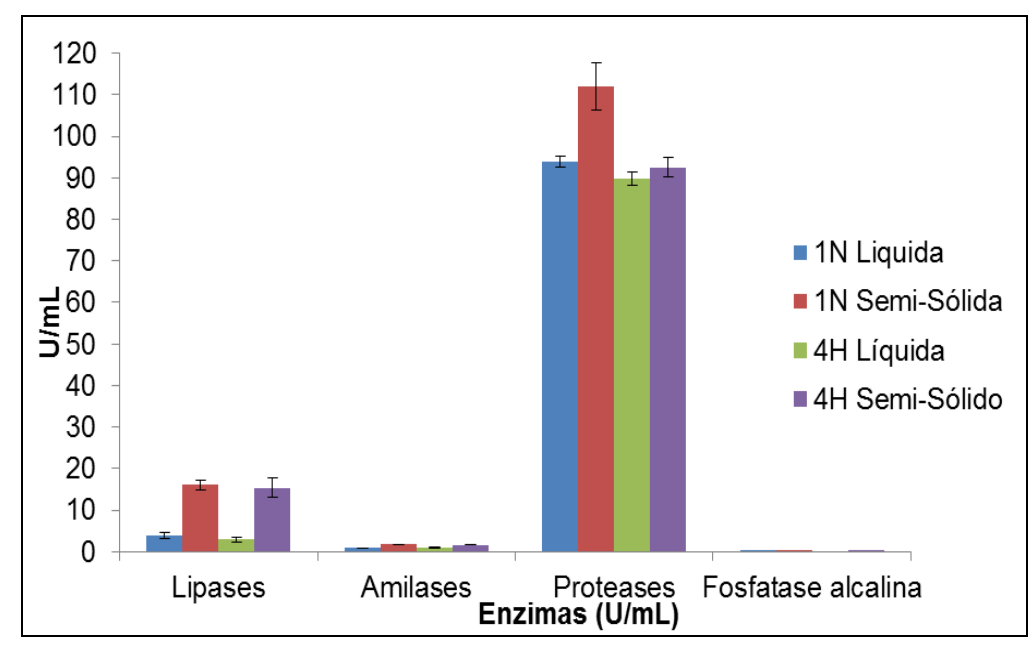

Figura 1 - Atividades enzimáticas (U/mL) dos complexos lipolítico, amilolítico, proteolítico e fosfatase alcalina, excretadas por Streptomyces sp. (1N e 4H) em fermentações em estado sólido (semi-sólida) e submersa, utilizando como fonte de carbono o resíduo da castanha-do-Brasil 


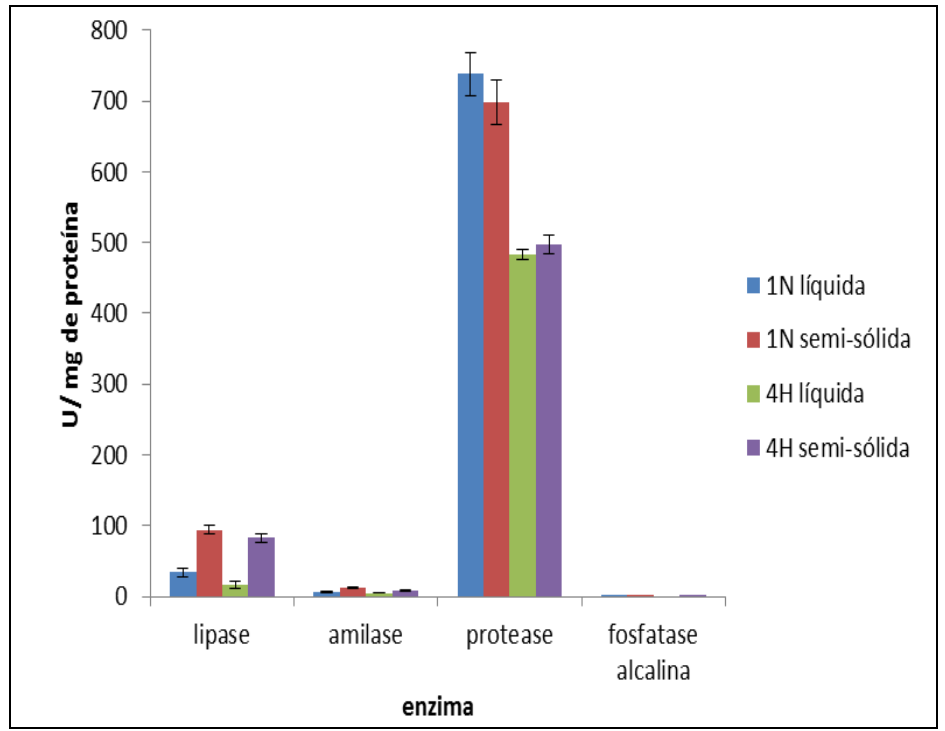

Figura 2 - Atividade específica (U/mg de proteína) dos complexos lipolítico, amilolítico, proteolítico e fosfatase alcalina, excretadas por Streptomyces $s p$. (1N e 4H) em fermentações em estado sólido (fermentações semi-sólidas) e submersa, utilizando como fonte de carbono o resíduo da castanha-doBrasil

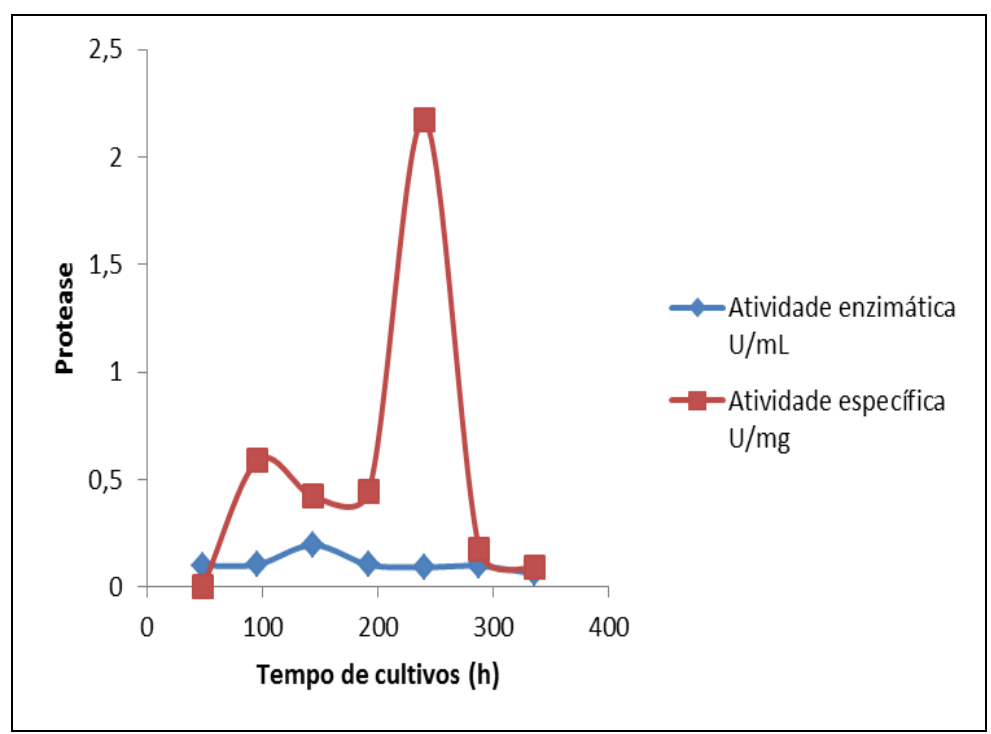

Figura 3 - Cinética das atividades enzimáticas e específicas da protease excretadas por Streptomyces sp. (1N) em fermentação em estado sólido (fermentação semi-sólida), utilizando resíduo da castanha-do-Brasil

Avaliando os resultados obtidos pela linhagem 4H para o complexo lipolítico detectou-se atividades em $\mathrm{U} / \mathrm{mL}$ e U/mg de proteína com 5,29 vezes e 5,00 vezes superiores aos respectivos valores obtidos nas fermentações submersas. Nos ensaios amilolíticos em fermentações em estado sólido a produção em $\mathrm{U} / \mathrm{mL}$ e U/mg de proteína foram respectivamente 1,03 e 1,71 vezes superiores aos valores detectados nas fermentações submersas.

Para as atividades proteolíticas produzidas pelas linhagens $1 \mathrm{~N}$ e $4 \mathrm{H}$ em $\mathrm{U} / \mathrm{mL}$ foram observados respectivamente valores de 1,19 e 1,03 superiores, comparados as suas fermentações submersas. Na análise de atividades específicas em U/mg de proteína não detectou-se diferença significativa para os dois modos fermentativos. 
Após o estudo da produção dos complexos enzimáticos no processo fermentativo, o complexo proteolítico que se destacou com maiores atividades, foi excretado pela linhagem 1N. A análise da cinética enzimática, descrita na figura 3, apresentou um perfil em U/mL com um pico majoritário de atividade enzimática de $0,196 \mathrm{U} / \mathrm{mL}$ a 144 horas de cultivo. Entretanto, avaliando o perfil cinético em atividades específicas (atividades enzimática por grama de proteína), presentes na figura 3, foi possível detectar a presença de dois picos enzimáticos sendo o majoritário obtido com 240 horas de cultivo e apresentado $2,16 \mathrm{U} / \mathrm{mg}$ de proteína.

De acordo com os dados da Figura 1, 2 e 3, em todos os experimentos realizados neste trabalho, a fermentação em estado sólido apresentou melhor atividade enzimática em $\mathrm{U} / \mathrm{mL}$, quando comparada a fermentação submersa. Nos últimos anos, a fermentação em estado sólido tem sido amplamente utilizada em diferentes aplicações no desenvolvimento de vários bioprocessos comercialmente importante (SÁNCHES et al., 2015).

\section{Considerações finais}

De acordo com os resultados obtidos neste trabalho foi observado que a linhagem de Streptomyces $s p$. (1N) foi a melhor produtora de enzimas hidrolíticas. Também constatou-se que o resíduo de castanha-do-Brasil apresentou excelentes resultados como uma fonte de carbono para a produção de enzimas hidrolíticas, possuindo um baixo custo, podendo ser utilizado nas indústrias.

Diante das fermentações utilizadas, a fermentação em estado sólido obteve os melhores resultados quando comparado com a fermentação submersa para a produção de lipase, amilase, protease e fosfatase alcalina.

Os resultados obtidos corroboram que a utilização de resíduo de castanha-do-Brasil se torna viável pelas indústrias como uma alternativa para produção de enzimas hidrolíticas devido ao seu baixo custo.

\section{Agradecimentos}

Os autores agradecem FAPEAM, pelo suporte financeiro para realização desse trabalho, e ao Departamento de Antibióticos (DANTI) da Universidade Federal de Pernambuco (UFPE).

\section{Referências}

ANZAI, K. et al. Actinomycete bactéria isolated from the sediments at coastal and offshore area of Nagasaki prefecture, Japan: diversity and biological activity. Journal of Bioscience and Bioenginering. 2008, v. 106, p. 215-217.

AWAD et al. Partial purification and characterization of extracellular protease from halophilic and thermotolerant strain Streptomyces pseudogrisiolus NC-15. Indian Journal of Biochemistry \& Biophysics. 2013, v. 50, p. 305-31.

BRADFORD, M. M. A rapid and sensitive method for the quantification of microgram quantities of protein utilizing the principle of protein-dye binding. Analytical Biochemistry. 1976, v. 72, p. 248-254.

COLLA et al. Aplicações e produções de lipases microbianas. Revista de ciências extas aplicadas e tecnológicas. 2012, v. 4, n. 2, p. 1-14.

CRUZ-JÚNIOR et al. Mulheres da floresta do vale do Guaporé e suas interações com o meio ambiente. Revista Estudos Feministas. 2012, v. 18, n. 3, p. 913-925. 
DAROIT, D. J. et al. Keratinolytic potential of a novel Bacillus sp. P45 isolated from the Amazon basin fish Piaractus mesopotamicus. Internation Biodeterioration and biodegradation. 2009, v. 63, p. 358-363.

DURAIPANDIYAN, V. et al. Antimicrobial properties of actinomycetes from the soil of Himalaya. Journal de Micologie Médicale. 2010, v. 20, p. 15-20.

GAMA, E.V.G. et al. Produção de biomassa de erva-cidreira Lippia alba (Mill.) N.E.Br] sob adubação com composto de capim elefante inoculado e sem inoculação de actinomicetos. Revista Brasileira de Plantas Medicinais. 2012, v. 14, p. 163-168.

HASAN, F., SHAH, A. A., HAMEED, A. Industrial applications of microbial lipases. Enzyme and Microbial Technology. 2006, v. 39, n. 2, p. 235-251.

HOLT, J.G., WILLIAMS, S.T., SHARPE, M.E. Bergey's manual of systematic bacteriology. Baltimore: Williams \& Wilkins, 1989. V. 4, p. 2300-2648.

HOMMA et al. Extrativismo vegetal ou plantio: qual a opção para a Amazônia? Estudos avançados. 2012, v. 26, n. 74, p. 167-186.

JAEGER, K.E.; DIJKSTRA, B.W.; REETZ, M.T. Bacterial Biocatalysts Molecular Biology, Three-Dimensional Structures, and Biotechonological Applications of Lipases. Annual Review Microbiology. 1999, v. 53, p. 315351.

LI, S. et al. Technology prospecting on enzymes: application, marketing and engineering. Computational and Structural Biotechnology Journal. 2012, v. 2, p. 1-1.

LOU, L. et al. Recent advances in industrial applications of lipases and strategies for improving lipase properties. Jounal of bioprocess Engieering and Biorefinery. 2013, v. 2, n. 2, p. 117-124.

MELO, E.S.R.L. Análise de biodegradabilidade dos materiais que compõem os resíduos sólidos urbanos através de ensaios BMP (BiochemichalMethanePotential). Recife. 2010. Dissertação (Mestrado em Engenharia Civil). Universidade Federal de Pernambuco, 2010.

MILLER, G. L. Use of dinitrosalicylic acid reagent for determination of reducing sugars, Analyical Chemistry. 1959 v. 31, p. 426-428.

MOSTAFA et al. Optimization conditions of extracellular proteases production from a Newly isolated Streptomyces pseudogrisiolus NCR - 15. E-Journal of Chemistry. 2012, v. 9, n. 2, p. 949-961.

NIGAM, P.S. Microbial enzymes with special characteristics for biotechnological applications, Biomolecules. 2013, v. 3, p. 597-611.

PACHECO, A.M.; VILDES, Castanha-do-Brasil: da floresta tropical ao consumidor. Florianópolis: Editorgraf, 2006, p 176.

PACHECO DA ROSA, J. et al. Streptomyces lunalinharessi strain 235 shows the potential to inhibit bacteria involved in biocorrosion processes. BioMed Research International, 2013, v. 2013, p. 1-10.

PANDEY et al. New developments in solid-state fermentation: I-Bioprocesses and products. Process Biochem. 2000, v. 35, p. 1153-1169.

PILLAI, P.; MANDGE, S.; ARCHANA, G. Statistical optimization of production and tannery applications of a keratinolytic serine protease from Bacillus subtilis P13. Process Biochemistry. 2011, v. 46, n. 5, p. $1110-1117$.

RAJU et al. Binding Macrolide Polyketides from an Australian Marine-Derived Actinomycete Nocardiopsis sp. Chemistry European Journal. 2010, v. 16, p. 3194-3200. 
ROSA, D. S.; PANTANO FILHO, R. Biodegradação: um ensaio com polímeros. São Paulo: Editora Universitária São Francisco, 2003.

ROWE, L; HOWAR, G.T. Growth of Bacillus subtilis on polyurethane and the purification and characterization of polyurethanase-lipase enzyme. International Biodeterioration \& Biodegradation. 2002, v. 50, p. 33 - 40.

SÁ et al. Coeficientes técnicos, custo e rentabilidade para a coleta de castanha-do-brasil no Estado do Acre: sistema de produção melhorado. Rio Branco: Embrapa Acre. p. 4, 2008.

SÁNCHES, L.B.R. et al. Fungal Lipase Production by Solid-State Fermentation. Journal of Bioprocessing \& Biotechniques. 2015, v. 5, n. 2, p. 2-9.

SHARMA, S.; KANWAWAR.S.S. Organic solvent tolerant lipases and applications. The Scientific World Journal. 2014, ID 625258, p. 15.

SANTOS, V.S. Desenvolvimento de barras de alto teor proteico a partir da castanha-do-Brasil. Dissertação (mestrado em Ciência e Tecnologia de Alimentos). Instituto de Tecnologia, Universidade Federal do Pará, Belém, 2008.

SOARES et al. Identificação do potencial amilolítico de linhagens mutantes do fungo filamentoso Aspegillus nidulans. Ciência e Tecnologia de Alimentos. 2010, v. 30, n. 3, p. 700-705.

TREICHEL, H et al. A review on microbial lipases production. Food and bioprocess technology. 2010, v. 3, n. 2, p. 182-196.

ZIMMER, K. R. et al. Enzimas microbianas de uso terapêutico e diagnóstico clínico. Revista Liberato, Novo Hamburgo. 2009, v. 10, n. 14, p. 123-137. 